\title{
Hyperspectroscopic and microtopographic analyses of salt crust forms on arid, silty clay loam desert soils
}

\author{
Fares M. Howari ${ }^{1}$, Fatima Al Aydaroos ${ }^{2}$, Yousef Nazzal ${ }^{1}$, Jibran Iqbal ${ }^{1}$ and Nadine Bou Orm ${ }^{1}$ \\ ${ }^{1}$ Zayed University, College of Natural and Health Sciences, P O Box 144534 Abu Dhabi, UAE \\ (corresponding author: fares.howari@zu.ac.ae; yousef.nazzal@zu.ac.ae; Jibran.lqbal@zu.ac.ae; Nadine.BouOrm@zu.ac.ae) \\ 2 UAE Space Agency, Abu Dhabi, UAE (F.AlAydaroos@space.gov.ae)
}

doi: $10.4154 / g c .2019 .01$

Article history:

Manuscript received February 16, 2018 Revised manuscript accepted October 11, 2018 Available online February 15, 2019

Keywords: Spectra, halite, gypsum, Rio Grande, soil, GER 3700

\begin{abstract}
This paper describes simultaneous uses of field sampling and hyperspectroscopic approaches to understand the distributions of salt crusts and factors affecting them under field conditions. Samples of salt affected soils and associated salt crusts that represented a range of soil salinities, slope, and moisture contents were gathered from the banks of the Rio Grande. The samples were studied for salt identification by optical microscopy and using a high-resolution spectroradiometer, GER 3700, and for salinity level, and moisture content by the wet chemistry method. The study identified two main groups of salt crusts, contaminated halite and gypsum crusts. Reflectivity was correlated negatively with moisture content and positively with slope value, electrical conductivity and salt quantity. Reflectivity of halite-dominated crusts was higher than those of gypsum. Halite occurred over a greater range and higher slope values of soils than gypsum; however, a positive correlation between the slope and mean reflectivity of both salt crusts was reported. Although reflectivity of salt crusts varied according to changes in moisture content, and the salinity of the soil, moisture content can drastically reduce the reflection more effectively? than the other factors. The data reported indicate the possibility of assessing the type of salt crust by estimation of the ratio of slope and reflectivity to the other variables.
\end{abstract}

\section{INTRODUCTION}

Agricultural soil worldwide is seriously vulnerable to production losses due to the accumulation of salt. The impact of salts from the agricultural water return flow and capillary rise from the high-water table in some locations, increases the variable concentration of sulphate and chloride salts in agricultural fields through space and time. Despite the general understanding of factors controlling salt distribution it remains difficult to extrapolate their spatial patterns on a large scale in the field. Thus, spatial tools and techniques are needed to set background conditions and verify variations in salt distribution and their impacting factors. However, the presence of additional mineral phases on the surface of the crusts might affect the reflectance spectrum of the crusts. The present study was conducted using field crust samples to evaluate the factors affecting their spectra and distribution.

Earlier studies reveal that soil characteristics and salt minerals can be identified by examining absorption features using semantic and computational approaches (HOWARI et al., 2002; DRAKE, 1995; CLARK, 1999; ZHANG et al., 2013; ARAUJO et al., 2014; SORIANO-DISLA JOSE et al., 2014; LAPOTRE et al., 2017; ROBERTSON et al., 2016; ARAUJO et al., 2014; WANG et al., 2018). The absorption of the visible part of the electromagnetic spectrum happens when anionic groups, such as sulphate and carbonate, and bonded $\mathrm{H}_{2} \mathrm{O}$ molecules are present. Since natural salts in soils contain these compounds, it is, in theory, possible to identify specific salt or evaporite minerals through spectral comparison with standard spectra libraries, identifying whether the evaporite is composed of pure minerals or admixtures. CSILLAG et al. (1993) conducted a study on the spectra of soil samples from San Joaquin in California and another set of samples from Hungary, specifically from the Carpathian Basin. They used a statistical approach in conjunction with a stepwise principal component band identification method to distinguish thirteen groups of soil salinity. They documented the significance of hyperspectroscopy techniques as a function of band width. The recognition accuracy decreased from 91 to $88 \%$ as the bandwidth decreased from 10-40 nanometers. The same study reported a positive correlation between the spectral pattern and the following parameters: clay fraction $(0.85)$, organic matter $(0.78), \mathrm{pH}$ $(0.75)$, salt fraction (0.73), and organic carbon (0.60).

Under field conditions, several factors affect the spectral profiles of salt crusts: the texture of the background soil, moisture content, and surficial contamination with other salts or minerals such as clay minerals or quartz. When an uncontaminated crust is developed as a result of evaporation of saline solutions, salt minerals with low solubility form first, and the surface of the crust is likely to be composed of salt minerals with the greatest solubility or in their sequence of their arrival at saturation (HOWARI, 2004). This hypothesis, solubility-controlled system, was previously tested under controlled conditions (HOWARI et al., 2000b, 2002; HOWARI et al., 2002). The purpose of the present study was to examine the factors controlling the distributions of the different types of salt crusts. This presents an opportunity to couple such hyperspectroscpic methods and databases with new airborne sensor technologies to deal with soil quality problems and enhance the quality of the soil mapping process.

\section{SOIL CHARACTERSTCS}

Salt crust samples were gathered from the upper 3-4 cm of the soil from the Rio Grande banks, three replicates were taken at each location for better representing the spatial variability of the 
sites in the vicinity of El Paso, Texas (Figure 1). Relative topographic slopes in the investigated area varied from 1.3 to $17.5 \%$. The general geology of the studied area is shown in Figure 2. The soil is generally composed of arid, silty clay loam desert soils without definite horizons, and very low organic matter. Visual observations in the field showed spotty salt crusts present in many areas around the sampled locations. Some of the soils appeared leached and in the wetter areas, dark colored, cracked silty clay soils were present. Areas along the bank and bed consist of alluvial or valley bottom very fine sand silty clay loams. The land surrounding the Valley is mostly soils developed from surrounding igneous geology, and fine-grained alluvial materials of the Rio Grande sediment system, which include quartz and clay minerals.

The bedrock of the study area is largely composed of limestone and dolomite. Caliche is formed when ground water rich in dissolved calcium carbonate from these source rocks leaches up into the soil, then evaporates or retreats, leaving the calcium carbonate behind. Over time, these soils are weathered by wind and rain, some soil is removed leaving only the hard cement-like caliche behind. This is why it is sometimes referred to as hard pan, because of the hard-impenetrable surface of exposed caliche in the soil. The major soils are mostly deep, brown or gray alkaline clays and loams. Some are saline. Most of the soils are used for rangeland to support grazing. Other part, the soil is used to grow irrigated grain sorghums and vegetables are grown along the Rio Grande (Figures 1 and 2).

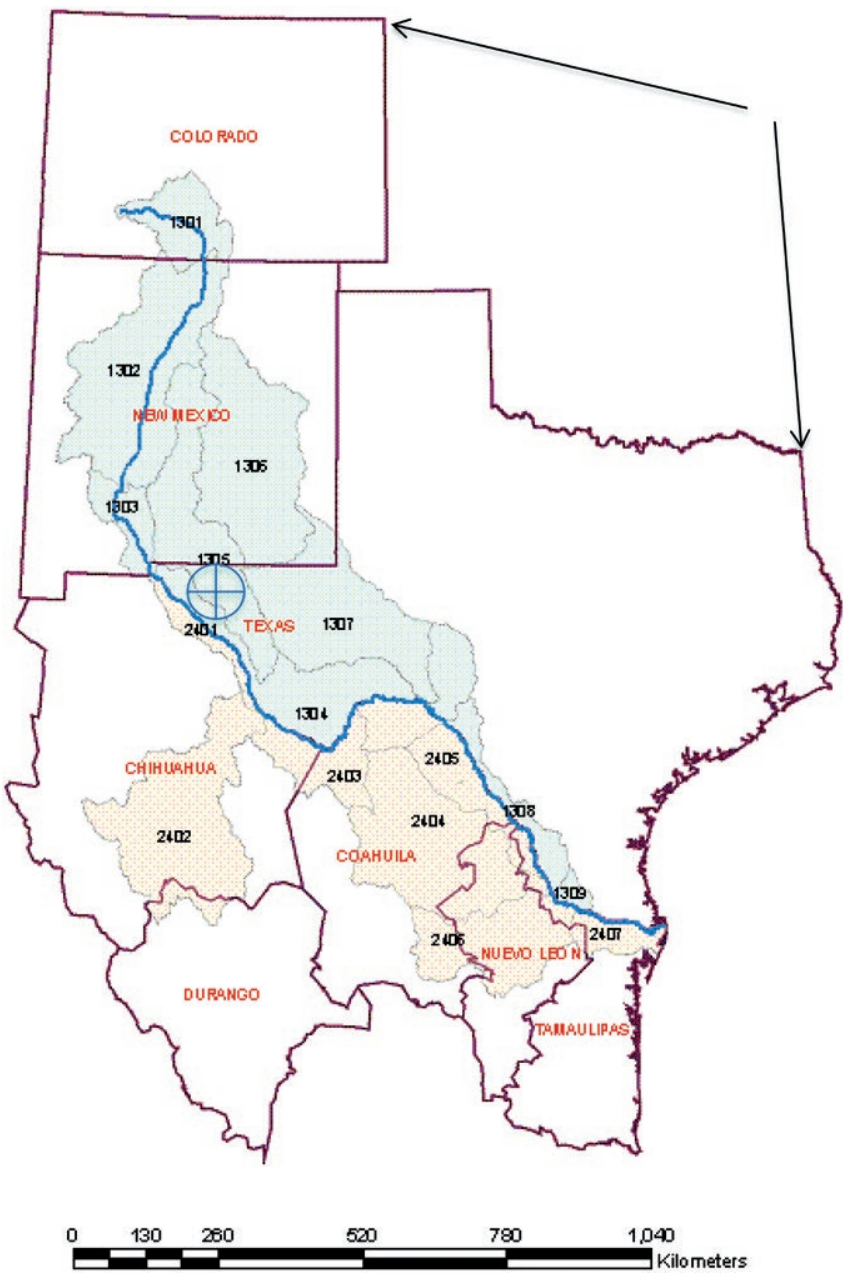

Figure 1. Location map of the study area.

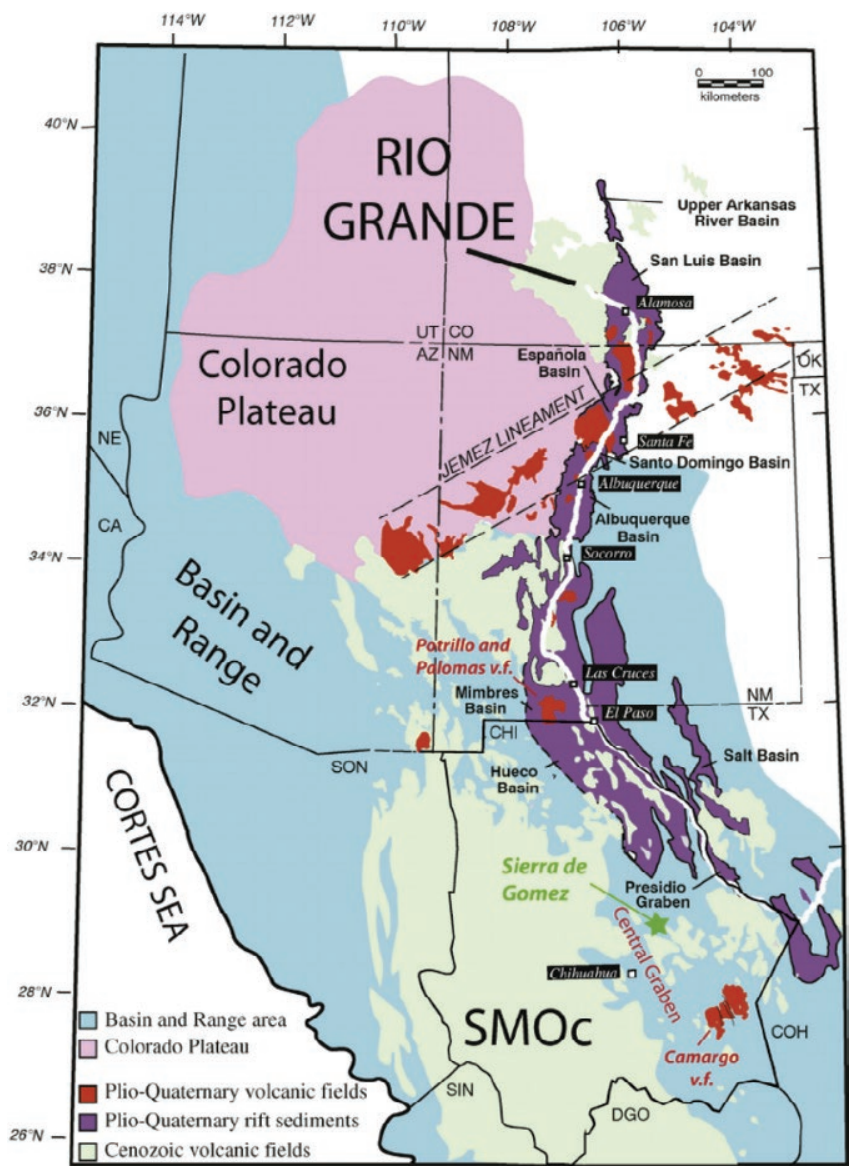

Figure 2. Main geological features of the Rio Grande valley showing (after VILLARREAL-FUENTES et al., 2016).
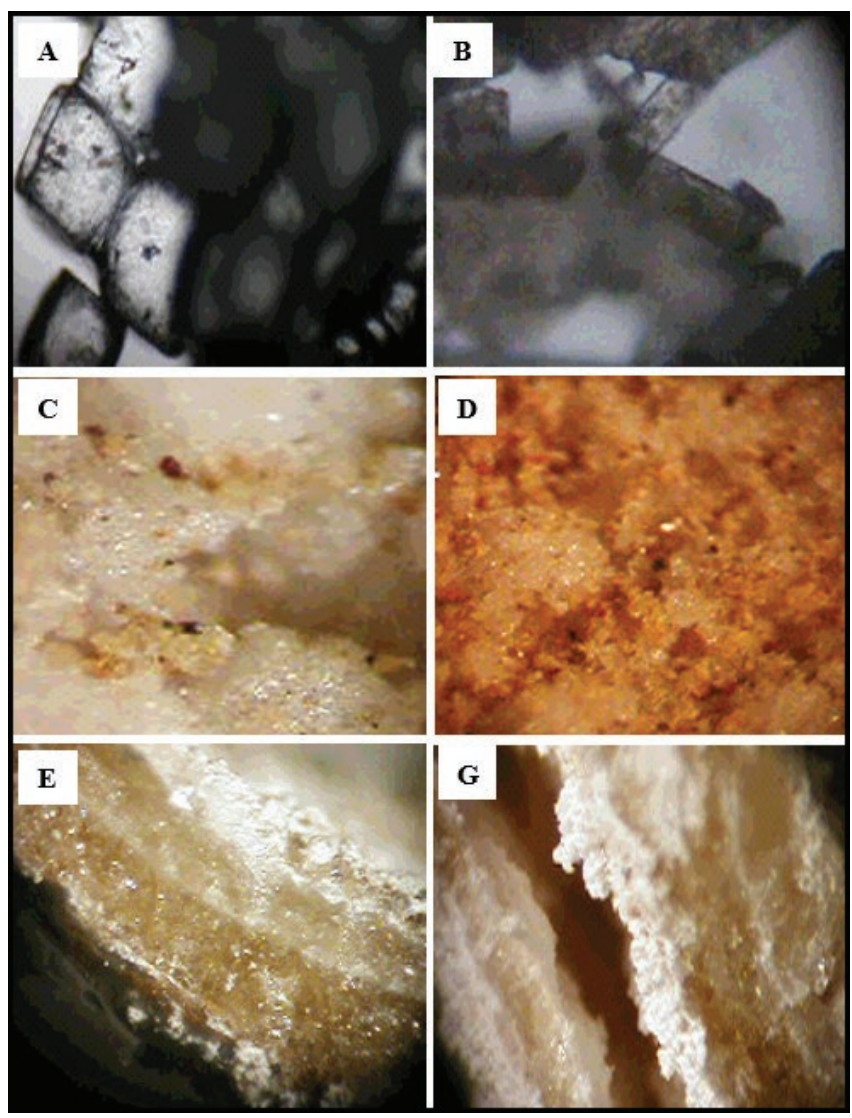

Figure 3. Salt crust as appear under optical microscope (A, and B; 100x) and under binocular microscope ( $\mathrm{C}$ to $\mathrm{G} ; 20 \mathrm{x}$ ). 


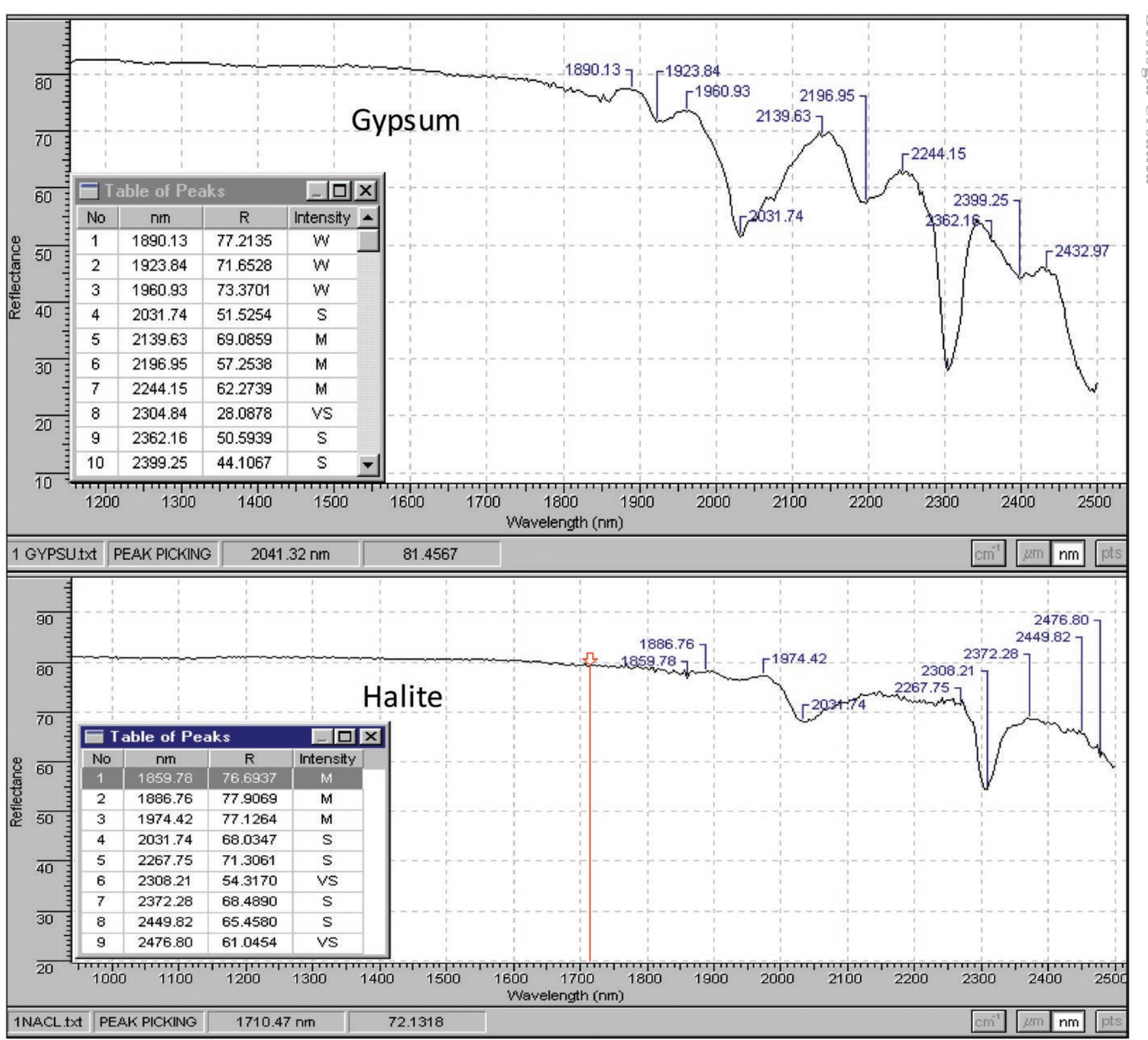

Figure 4. Reflection spectra of halite and gypsum $(250-2500 \mathrm{~nm})$.

\section{METHODOLOGY}

Soil samples $(n=25)$ beneath the crusts were selected randomly from a salinized flood plan area tested for salinity by measuring electrical conductivity (EC) of a saturation extract, through a saturated soil paste made by gently dripping deionized $\mathrm{H}_{2} \mathrm{O}$ onto about $150 \mathrm{~g}$ of soil until the mixture became thick (e.g. WANG et al., 2018). The thick paste was left for 2 hours before it was filtered by suction. The EC was measured on the filtrate using an EC-meter and reported as $\mathrm{dS} / \mathrm{m}$. Measurement of soil moisture, and salt contents were determined by gravimetric methods. Clinometers were used to measure the gradient of the soil surface. The salt crusts were tested using microscopic techniques with a Nikon-Eclipse ME600L, and Olympus microscopes. Testing was accomplished under transmitted light at magnification up to $600 \mathrm{x}$ for crystal characterization and to determine optical attributes. The salt crust was also investigated under cross polarized light for pleochroism, interference colors and birefringence of anisotropic crystals as well as under plane polarized light for crystal habit and relief.
Before taking the spectral reading, the water content in the soil samples was standardized by drying in an oven at $40^{\circ} \mathrm{C}$ for 24 hours to prevent chemical alteration and therefore changes in soil sample compositions. Soon after, the soil samples were inserted in a desiccator for at least 24ours until the spectral readings were taken. The spectral reflectance reading from salt crusts was taken with a high-resolution spectroradiometer (MODEL GER 3700) in a wavelength range from 500 to $2500 \mathrm{~nm}$. This treatment was performed on a fraction of the collected samples in order to identify the minerals, another spectral run were performed on the bulk samples to study the impact of moisture content on the reflectance signatures. However, before starting the spectral reading, the instrument was calibrated by fixing it on a stand to measure the reflectance of its special white calibration panel. More details on spectral measurements are reported in HOWARI et al. (2002).

The spectral profiles were studied by computerized peak picking techniques using a spectral software package (Specview). Comparison between the groups and subgroups of samples involved use of Analyses of Variance (ANOVA) One Way Layout 

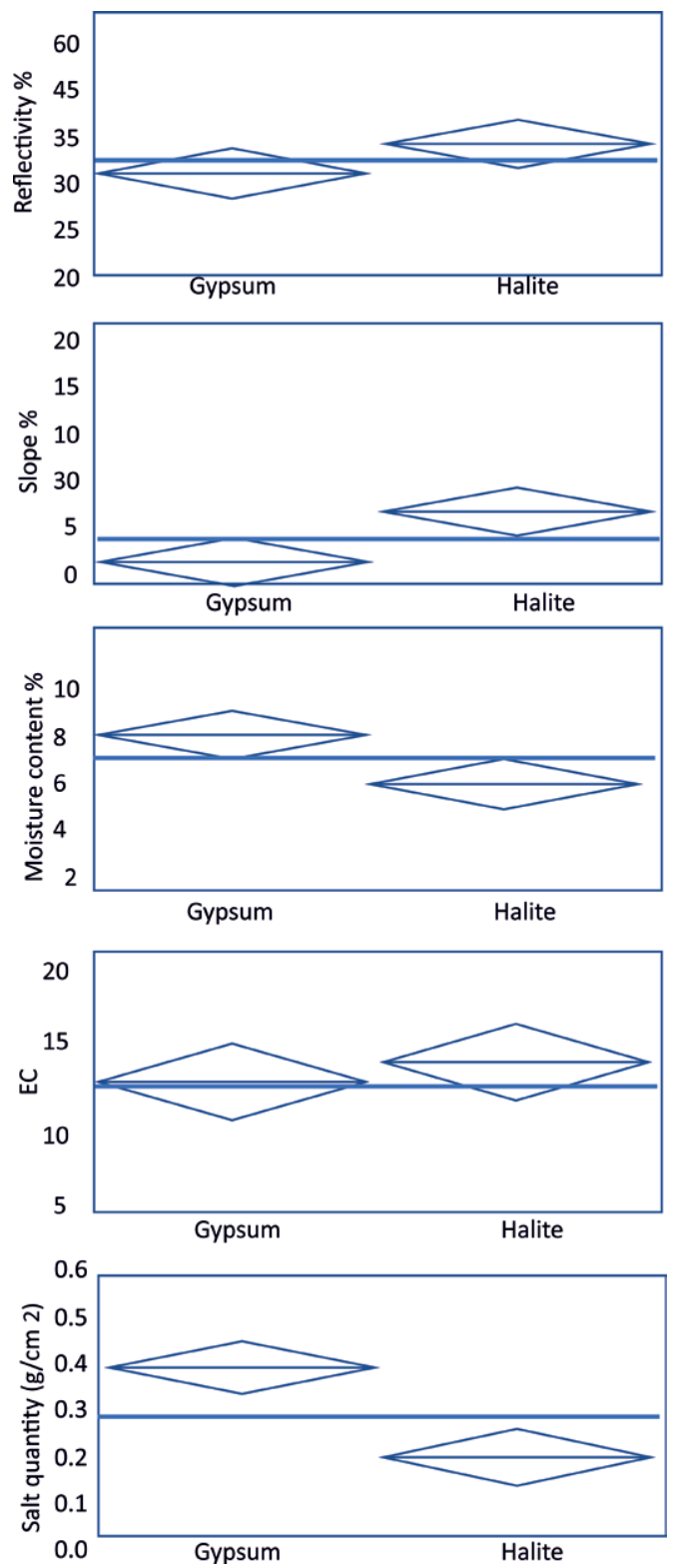

Figure 5. Soil characteristics under the gypsum and halite crust.

design, Principal Component Analyses (PCA) and the F-test using Excel and JMP/SAS software packages (SALL \& ANN, 1996). Processed data were compared with the spectral data from NASA and USGS spectral libraries, and the spectral profiles and findings reported by CROWELY (1991), DRAKE (1995), and HOWARI et al. (2000 a, b and 2002). The data was firstly summarized and then the spectra were presented in terms of the mean plus and minus the standard deviation. Then the emphasis was placed on evaluating which factors govern the greater variability of reflectance and crust formation.

\section{RESULTS AND DISCUSSION}

Halite crusts have a glassy, transparent appearance with white to colorless, cubic to euhedral crystals (Fig. 3 a). The surfaces of halite crusts were contaminated with quartz grains, and a claylike surface cover (Fig. 3c). Gypsum crusts appeared as white, transparent to translucent, and had prism-like to monoclincal shapes, with earthy to vitreous lustre. Lamellae of successive zones of halite and gypsum crusts were observed in cross-sections prepared for crust collection (Fig. 3).
The shape of the spectral profile as well as the shape and location of the of the absorption band are significant in identifying and interpreting the spectral properties of salt crusts. The outlook of a spectral profile can be identified by the continuum slope and the intensity distribution, and the albedo. Although albedo is the main source of variability, absorption characteristics have an important role in relation to certain chemical properties. In the tested soil samples, the highest reflectance value ranged from $25 \%$ to $45 \%$ (Table 1). There are five regions of the mean spectra that demonstrate unique absorption properties and high differences among the tested soil spectra. These are located around 1000, 1400, 1900, 2200, $2300 \mathrm{~nm}$ (Fig. 4).

A crust with a certain grain size will have a particular reflectance, as when grain size changes, reflectance changes accordingly. It may increase or decreases as a function of the transparency and opacity of the material. Halite, which cannot induce absorption bands in the visible and near thermal infrared (HUNT et al., $1971 \mathrm{a}, \mathrm{b}$; MOUGENOT et al., 1993) had visible absorption features due to moisture and fluid inclusions or due to contamination and was placed at 1500, 1884, and $2245 \mathrm{~nm}$ (Fig. 4).

The surface of halite crusts is contaminated with materials from the surrounding soils which have plenty of quartz grains, and clay minerals (Fig. 3). Quartz is translucent, therefore, when its proportion in the soil or soil crust increases, light will more easily be transmitted through the crust, strengthening the detected band strength of absorbance properties in the reflectance spectra of halite crusts contaminated with quartz. The study observed a minor absorption feature present at $2310 \mathrm{~nm}$. Although not very visible, this absorption is related to the combination of -OH stretching mode with $\mathrm{Mg}-\mathrm{O}-\mathrm{H}$ bending mode, and it is present in trioctahedral clays as described by PIETERS \& ENGLERT (1993) and EL-RADAIDEH et al. (2017).

The spectra shown in Figure $3 \mathrm{~b}$ had strong absorption features at 1024, 1226, 1780, and $2337 \mathrm{~nm}$, and even stronger ones at 1458,1866 , and $1989 \mathrm{~nm}$. Those absorption features are known for gypsum. In gypsum the overtones or combination tones from fundamental vibrations of the water molecules produced a series of bands affecting the infrared spectrum between 1000 and 2500 nm, e.g. 1464, 1550, 1750, 1978 and $2300 \mathrm{~nm}$ (CLARK, 1999 and HOWARI et al., 2002). These can be detected in the spectra of gypsum crusts (Fig. 4a). However, the most dominant absorption features occurred at 1464, 1750 and $1978 \mathrm{~nm}$.

Table 1. Correlation and test of significant among the studied soil parameters.

\begin{tabular}{llccc}
\hline Variable & by Variable & Correlation & Count & Signif Prob \\
\hline Reflectance & Slope & 0.1744 & 25 & 0.4044 \\
EC & Slope & 0.2735 & 25 & 0.1858 \\
EC & Reflectance & 0.3526 & 25 & 0.0839 \\
Moisture & Slope & -0.3827 & 25 & 0.0590 \\
Moisture & Reflectance & -0.1709 & 25 & 0.4139 \\
Moisture & EC & -0.5094 & 25 & 0.0093 \\
Quantity & Slope & -0.2633 & 25 & 0.2035 \\
Quantity & Reflectance & -0.2422 & 25 & 0.2434 \\
Quantity & EC & -0.1560 & 25 & 0.4564 \\
Quantity & Moisture & 0.3115 & 25 & 0.1296 \\
Quantity & Slope & -0.2633 & 25 & 0.2035 \\
Quantity & Reflectance & -0.2422 & 25 & 0.2434 \\
Quantity & EC & -0.1560 & 25 & 0.4564 \\
Quantity & Moisture & 0.3115 & 25 & 0.1296 \\
Quantity & g/cm2 & 1.0000 & 25 & 0.0000 \\
\hline
\end{tabular}




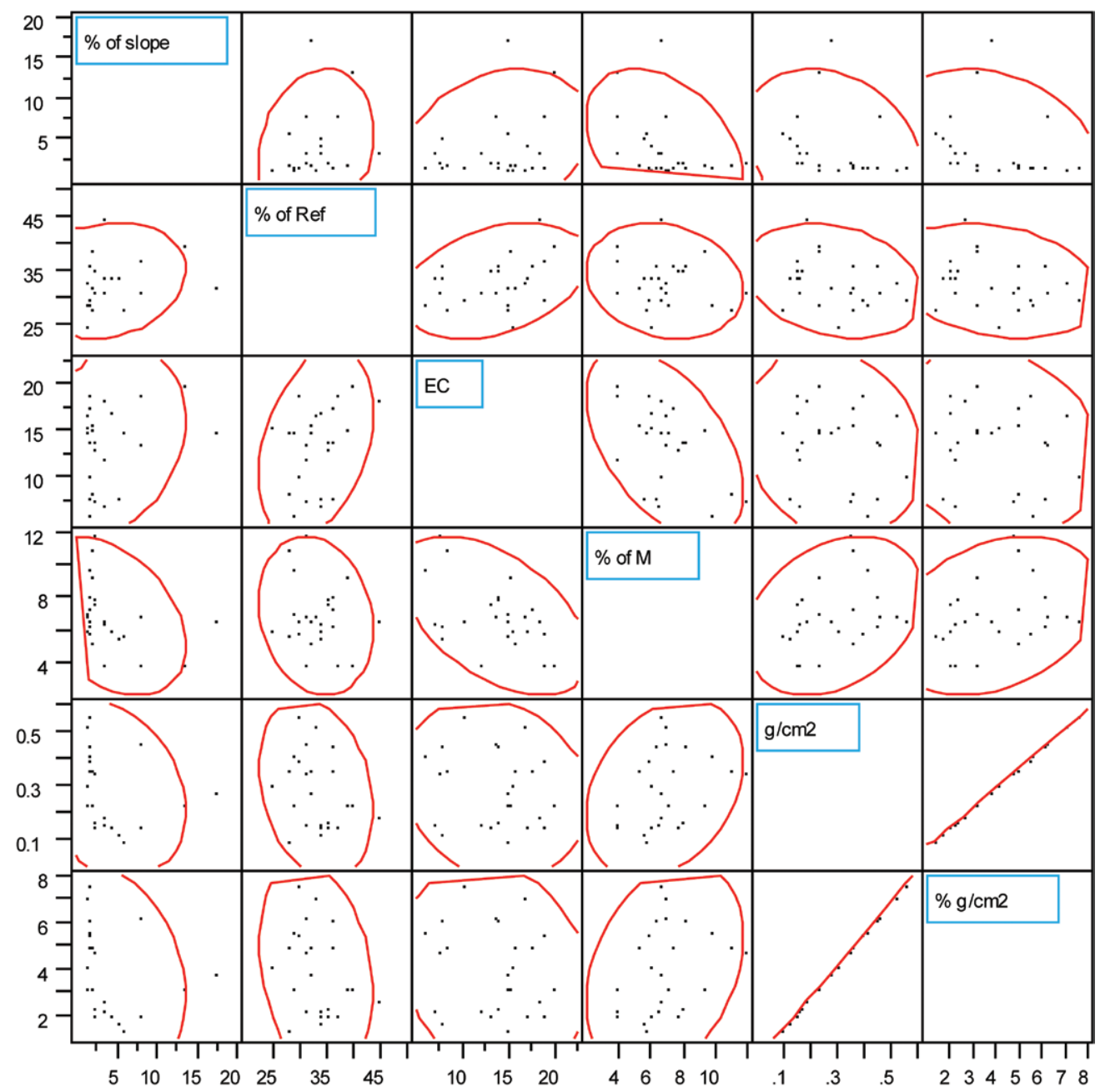

Figure 6. Scatter plot illustrating the relationship between percent of low soil reflectivity and soil characteristics.

Comparison of a group of variable differences obtained from gypsum and halite crusts is shown in Figure 5, and Table 2. A tool called a "diamond plot" was used to visualize the variability and results are shown in Figure 4. It condensed essential information, group means, grand sample mean (the horizontal line in
Figure 5), confidence interval (CI), and raw data. A horizontal dotted line represents the grand sample mean. The diamond is the confidence interval for each group and the horizontal line within each diamond is the group means. The flatter the diamond, the tighter the $\mathrm{CI}$. The groups of variables for halite concentrate

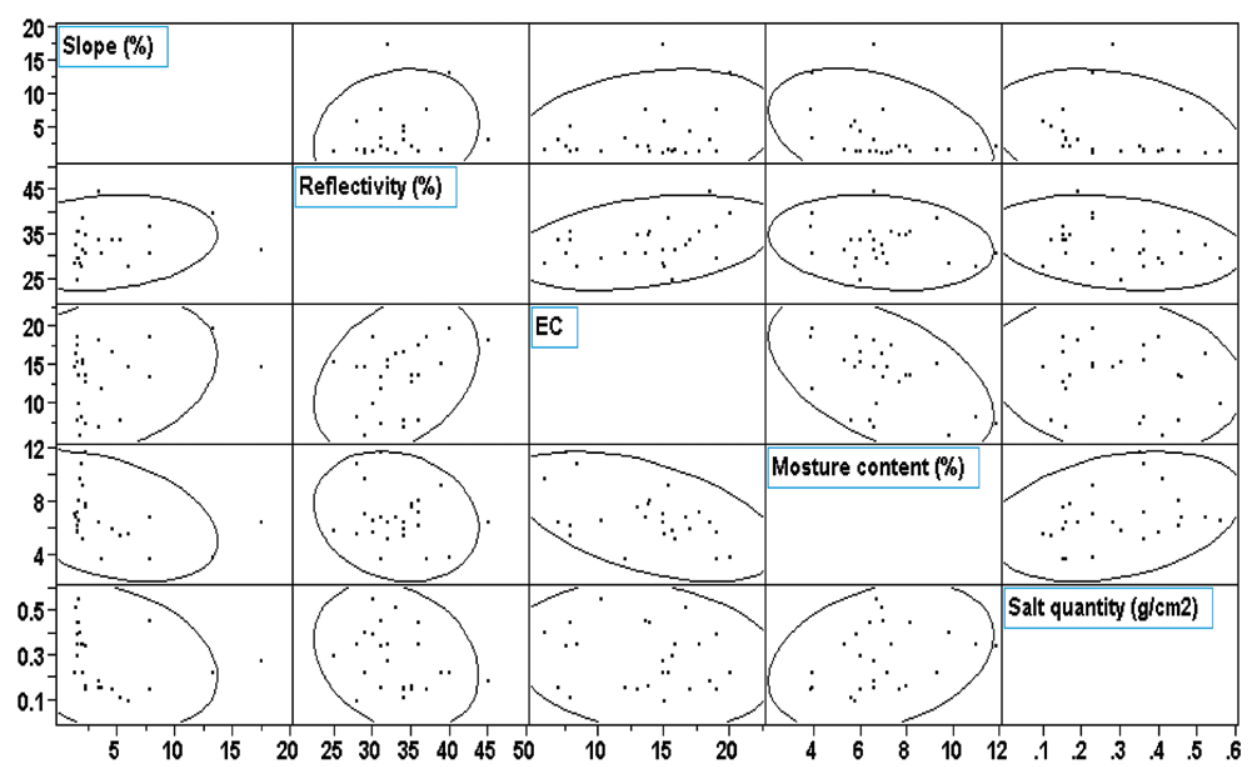

Figure 7. Scatter plot illustrating the relationship between surface slop and percent of reflectivity. 


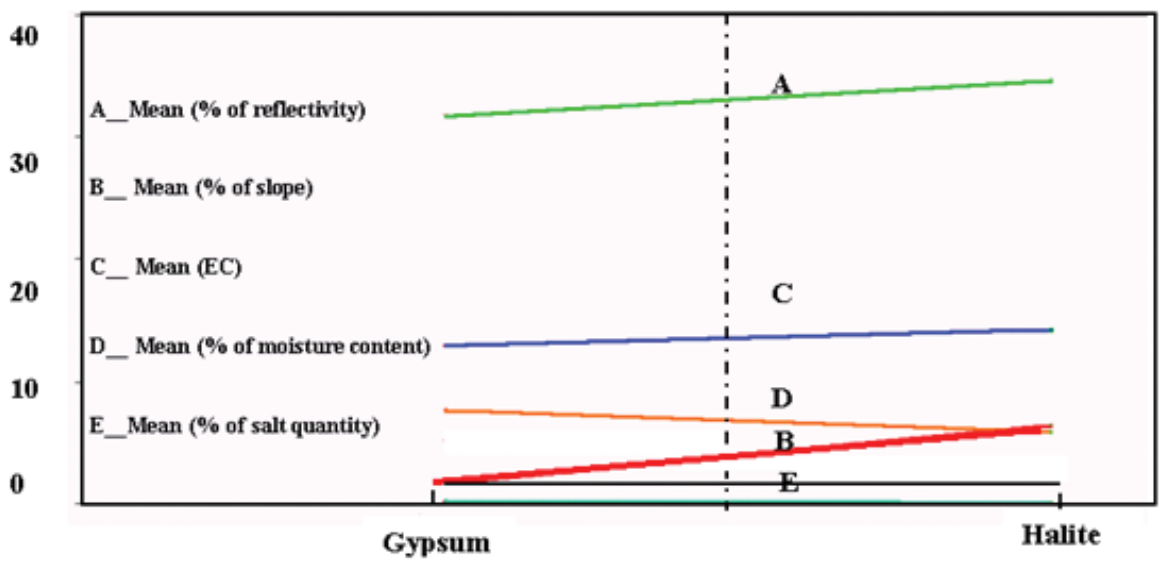

Figure 8. Ratio of the surface slope and reflectivity to other soil characteristics.

around the mean in a different pattern to those of gypsum. For example, reflectivity and value of gypsum concentrate below the grand mean and those of halite above the ground mean. Testing the soil samples with low reflectance demonstrated that all of these also have high moisture content (Figs. 6 and 7). The absorption bands are observed more clearly when the underlying soil samples have higher salt contents (Fig 7). In the presented scatter plots, the ellipses surrounding the data points represent the $95 \%$ bivariate normal density ellipse, which is shown in each scatterplot. If each pair of variables has a bivariate normal distribution, this ellipse encloses approximately $95 \%$ of the points. The narrowness of the ellipse reflects the degree of correlation of the variables. If the ellipse is fairly round and is not diagonally oriented, the variables are uncorrelated. If the ellipse is narrow and diagonally oriented, the variables are strongly? correlated.

Correlations derived from the whole data sets yielded poor to good results, positive poor correlation was recorded between crust reflectivity and soil EC values with a significance probability of 0.08 , whereas a negative correlation was recorded between reflectivity and moisture values with a significance probability of 0.4 . A correlation coefficient of 0.4 is significantly stronger depending on the sample size and critical value for the number of data pairs. The correlation between slope and reflectivity was positive with significant probability of 0.4 , indicating that slope is a relatively controlling factor for crust reflectivity (Table 2, Fig. 7). However, the mean of the relative slope for halite occurrences was $6.4 \%$ and for gypsum was $1.7 \%$. This could be due to drainage properties when drainage and slope gradient is efficient, and during the wet season the salts such as sodium chloride are washed down through the soil. This could suggest that soil with poor surface drainage will have much higher halite/gypsum ratios than soil in an area with good surface drainage. Principal Component Analyses (PCA) was applied to show which factor

Table 2. Descriptive statistics of the studied soil samples.

\begin{tabular}{lccccc}
\hline Parameter & $\begin{array}{c}\text { Reflectivity } \\
(\%)\end{array}$ & $\begin{array}{c}\text { Slope } \\
(\%)\end{array}$ & EC & $\begin{array}{c}\text { Salt Quantity } \\
\left(\mathrm{g} / \mathrm{cm}^{2}\right)\end{array}$ & $\begin{array}{c}\text { Moisture } \\
(\%)\end{array}$ \\
\hline Minimum & 25 & 1.32 & 6 & 1.36 & 3.86 \\
Maximum & 45 & 17.55 & 19 & 7.67 & 11.86 \\
Mean & 32.91 & 3.61 & 13.36 & 7.03 & 7.03 \\
Standard error & 0.863 & 0.72 & 0.82 & 0.38 & 0.39 \\
Median & 32.5 & 2.13 & 14.4 & 3.97 & 6.63 \\
Standard deviation & 4.23 & 3.56 & 4.06 & 1.89 & 1.93 \\
Sample variance & 17.9 & 13.68 & 16.5 & 3.58 & 3.75 \\
\hline
\end{tabular}

Table 3. Principal component analyses among the studied variables.

\begin{tabular}{lccccc}
\hline $\begin{array}{l}\text { Principal } \\
\text { Components }\end{array}$ & PC1 & PC2 & PC3 & PC4 & PC5 \\
\hline EigenValue: & 2.6656 & 1.3282 & 0.892 & 0.7005 & 0.4137 \\
Percent: & 44.4272 & 22.1362 & 14.8662 & 11.6751 & 6.8954 \\
CumPercent: & 44.4272 & 66.5633 & 81.4295 & 93.1046 & 100 \\
Slope & -0.34024 & 0.24565 & -0.45603 & 0.77205 & 0.14093 \\
Reflectance & -0.2967 & 0.21914 & 0.8078 & 0.33429 & -0.31568 \\
EC & -0.33737 & 0.55637 & 0.13165 & -0.3669 & 0.65168 \\
Moisture & 0.4026 & -0.36501 & 0.34914 & 0.37881 & 0.66279 \\
Quantity & 0.51005 & 0.47374 & -0.0114 & 0.0839 & -0.09087 \\
\hline
\end{tabular}

produce the greatest variability in the data (Table 3). The analyses demonstrated that differences developed by salt quantity and slopes were grouped in the first and second PCs respectively. The low concentration of salts in the samples was considered a determining property for expression of the reflectance features. Soils with salt content had low reflectance, primarily expressed through the first PC. The third source of variability produced from variations in moisture content that is correlated negatively with reflectivity, and slope. Figure 8 shows a graphical representation of the ratio of the slope and reflectivity of gypsum and halite crusts as they relate to the other studied soil variables. It is possible to use this relationship to assess the type of crusts present. This could have several applications in reclamation appraisals, salinity management and in precision agriculture or satellite farming.

The data presented demonstrate the influence of interlinked factors in controlling the field spectra. However, the spectra of salt crusts change with natural wetting or drying cycles or with man induced effects such as sprinkler irrigation, and this question is being investigated by comparing field and lab spectra simulated under various conditions including wetting, drying and spraying. Once obtained, this knowledge together with previous data (e.g. CROWELY, 1991; DRAKE, 1995 and HOWARI et al., 2000 a, b and 2002) can be employed for agricultural land planning, management and reclamation purposes.

\section{CONCLUSION}

Although different interlinked factors were found to affect the reflectivity of gypsum and halite, their spectra remained recognizable. The reflectivity of salt crusts varied according to changes in moisture content, and the salinity of the soil drastically reduced the reflection much more than other factors. Halite occurred at high soil slope value than gypsum; however, positive correlation 
between the slope and mean reflectivity of both salt crusts was reported. It was difficult to assess the order of factors controlling the reflectivity and formation of salt crusts and their alternation in the following suggesting orders, for halite: salt quantity $>$ slope $>$ moisture content; and for gypsum: moisture content $>$ salt quantity $>$ slope. The present results are encouraging for assessing the type of salt crust by estimating the ratio of slope and reflectivity to the other variables.

\section{ACKNOWLEDGMENT}

The author would like to extend our thanks and appreciation to the Pan American Center for Earth and Environmental Studies at UTEP for the technical assistance and UAE Space Agency for funding part (data processing) of this research (Z01-2016-001). Special thanks for the valuable comments from Dr. S. MIYAMOTO from Texas A\&M University, Agricultural Research Center at El Paso.

\section{REFRENCES}

ARAUJO, S.R., WETTERLIUD, J., DEMATTE, J.A.M. \& STENBERG, B. (2014): Improving the prediction performance of a large tropical vis-NIR spectroscopic soil library from Brazil by clustering into smaller subsets or use of data mining calibration techniques.- European Journal of Soil Science, 65/5, p. 718

BECK, R.H., ROBINSON, B., MCFEE, W.W. \& PETERSON, J.B. (1976): Spectral characteristics of soils related to the interaction of soil moisture, organic carbon, and clay content; LARS Inf. Note 081176.- Purdue University, West Lafayette, Indiana.

BEN-DOR, E., IRONS, J.R. \& EPENA, G.F. (1999): Soil reflectance.- In: RENCES, A.N. (ed.): Remote sensing for earth sciences: manual of remote sensing, 3 ed., vol. 3, John Wiley and Sons Inc, USA, 111-188.

BRIGGS, M. (1996): Riparian ecosystems recovery in arid lands, strategies and references.- Tuscon, AZ: University of Arizona Press, 159 p.

BUSCH, D.E. \& SMITH, S.D. (1993): Effects of fire on water and salinity relations of riparian woody taxa.- Oecologia, 94, 186-194.

CLARK, R.N. (1999): Spectroscopy of rocks and mnerals and principles of spectroscopy.-In: RENCES, A.N. (ed.): Remote sensing for earth sciences: manual of remote sensing, 3 ed., vol. 3, John Wiley and Sons Inc. USA., 1999, 3-52.

CONDIT, H.R. (1970): The Spectral reflectance of American soils.- Photogramm. Eng., $36,955-966$

CROWLEY, J.K. (1991): Visible and near-infrared (0.4-2.5 micron) reflectance spectra of playa evaporate minerals.- Journal of Geophysical Research, 96, 16231-16240.

CSILLAG, F., PASZTORE, L. \& BIEHL, L.L (1993): Spectral selection for characterization of salinity status of soils, Remote Sensing of the Environment, 43, 231-242.

DRAKE, N.A. (1995): Reflectance spectra of evaporite minerals (400-2500 nm): applications of remote sensing.- Int. J. Remote Sensing, 16/14, 2555-2571.

EHLERS, E.G. (1987): Optical mineralogy, Vol. 1, Theory and Techniques, Vol. 2 Mineral Description.- Blackwell Scientific Publication, Palo Alto, Calif., $158 \mathrm{p}$

EVERITT, J.D., ESCOBAR, D.E., GERBERMANN, A.H. \& ALANIZl, M.A. (1988): Detecting saline soils with video imagery.- Photogramm. Eng. Remote Sensing, $54,1283-1287$

EXCEL (2000): Microsoft Corporation, Redmond, Washingnton, 98052, USA.

EL-RADAIDEH, N., AL-TAANI, A.A. \& AL KHATEEB, W.M. (2017) Characteristics and quality of reservoir sediments, Mujib Dam, Central Jordan, as a case study.Environ Monit Assess, 189, 143 p.

GLENNl E.R., TANNER, S., MENDEZ, T., KEHRET, D., MOORE, GARCIA, J. \& VALDES, C. (1998): Growth rates, salts tolerance and water reuse characteristics on native and invasive riparian plants from delta of the Colorado River, Mexico.Journal of Arid Environment, 40, 281-294.

HOWARI, F.M., GOODEL, P.C. \& MIYZMOTO, S. (2002): Spectral properties of salt crusts formed on saline soils, Environ.- Qual., Vol. 31, 1453-1461.

HOWARI, F.M., GOODEL, P.C., MIYZMOTO, S. \& PENN, B. (2000a): Spectral properties of treated silty clay loam and fine sandy loam with gypsum, halite and their mixtures: Remote Sensing 2000, From Laboratory Spectroscopy to Remotely Sensed Spectral Observation. Soil Science Society of America, Corpus Christi, Texas. Blackland Research and Extension Center, TX. 2-27.

HOWARI, F.M., GOODEL, P.C., MIYZMOTO, S. \& PENN, B. (2000): Spectral properties of gypsum, halite and their mixtures: Fourteenth International Conference and Workshop on Applied Geologic Remote Sensing (An abstract), Las Vegas. Nevada, Nov. 6-8.

HOWARI, F.M., GOODEL, P.C., MIYZMOTO, S. \& PENN, B. (2000c) Spectral reflectance characteristics of salt deposited on the soil surfaces. Second EARSel Workshop on Imaging Spectroscopy, ITC, the Netherlands, July 11-12. Proceeding on compact diskette, ITC, Enshide, the Netherlands, 40, 1-11.
HUNT, G.R., SALISBURY, J.W. \& LENHOFF, C.J. (1971a): Visible and near-infrared spectra of minerals and rocks. IV. Sulphides and sulphates.- Mod. Geology, 3, 1-4.

HUNT, G.R., SALISBURY, J.W. \& LENHOFF, C.J. (1971b): Visible and near-infrared spectra of minerals and rocks. III. Oxides and Hydroxides.- Mod. Geololgy, 2, 195-205.

HUNT, G.R. (1982): Spectroscopic properties of rocks and minerals.- In: CARMICHAEL, R.S. (ed.): Handbook of Physical properties of rocks, Vol. I. CRC Press, Boca Raton, 295-385.

HUNT, G.R. \& SALISBURY, J.W. (1970): Visible and near infrared spectra of minerals and rocks. I. Silicate minerals.- Mod. Geology, 1, 283-300.

INTERNATIONAL SOIL REFERENCE \& INFORMATION CENTRE (ISRIC)(1990): World map of the status of human-induced soil degradation. United Nations Environmental Program.- Wagenngen JMP/SAS, 1999. SAS Institute Inc. Cary, NC, 27513, USA

LAPOTRE, M.G.A., EHLMANN, B.L. \& MINSON, S.E.A. (2017): Probabilistic approach to remote compositional analysis of planetary surfaces.- Journal of Geophysical Research: Planets, 122, 983-1009.

MASSOUD, I. I. (1990): Salinity and alkalinity as soil degradation hazards.-FAO, Rome. METTERNICHT, G. \& ZINK, A. (1997): Spatial discrimination of salt and sodium affected soil surfaces.- International Journal of Remote Sensing, 18, 2471-2486.

MIYAMOTO, S. (2000): Soil resources of El Paso, characteristics, distribution, and management guidelines.- Texas A and M University Agricultural Research Center at El Paso, Texas, USA.

MOUGENOT, B., EPEMA, G.F. \& POUGET, M. (1993): Remote sensing of salt affected soils.- Remote Sensing Review, 7, 241-259.

MULDERS, M.A. (1987): Remote sensing in soil science, developments in soil science.Elsevier, Amsterdam. The Netherlands, 379 p.

NESSE, W.D. (1991): Introduction to optical mineralogy, $2^{\text {nd }}$ ed.- Oxford University Press, New York.

OBKUHOVbk, A.I. \& ORLOV, D.S. (1964): Spectral reflectivity of the major soil groups and possibility of using diffuse reflection in soil investigation.- Sov. Soil Sci (Engl. Trans), 2, 174-184.- In: GHASSEM, A. (ed.): Theory and Applications of Optical Remote Sensing. Wiley Series in Remote Sensing, John Wiley, 1989, USA, 734 p.

PIETERS, C.M. \& ENHLERT, P.A.J. (1993): Remote Geochemical Analyses: Elementaland Mineralogical Composition.- Cambridge Univ. Press, New York.

RHOADESh, R.J. \& MIYAMOTO, S. (1990): Testing soils for salinity and sodicity.- In: WESTERMAN, R. (ed.): Soil testing and plant analysis. ASA Publication Series \# 3, 299-336.

ROBERTSON, K., MILLIKEN, R. \& LI, S. (2016). Estimating mineral abundances of clay and gypsum mixtures using radiative transfer models applied to visible-near infrared reflectance spectra Icarus, 277, 171-186.

SHELLEY, D. (1985): Optical mineralogy, $2^{\text {nd }}$ ed.- Elsevier Science Publisher, New York, $321 \mathrm{p}$.

SORIANO-DISLA JOSE, M., JANIK LES, J., VISCARRA ROSSEL RAPHAEL, A., MACDINALD LYNNE, M. \& MCLAUGHLIN MICHAEL, J. (2014): The Performance of Visible, Near-, and Mid-Infrared Reflectance Spectroscopy for Prediction of Soil Physical, Chemical, and Biological Properties.- Applied Spectroscopy Reviews, 49/2, p. 139.

SPEC-VIEW, (1992): Jet Propulsion Laboratory (JPL) and United States Geological Survey, Pasadena, California, 91109, USA.

STONERE, E.R. \& BAUMDARDNER, M.F. (1981): Characteristic variation in reflectance of surface soils.- Soil Sci. Soc. Am. J., 45, 1161-1165.

SUMMER, E.M. \& NAIDU, R. (1998): Sodic soils, distribution, properties, management, and environmental consequences.- Oxford University Press, USA, 207 p.

SUMMER, M.E. (2000): Handbook of soil science.- CRC Press., Boca Raton., USA., $418 \mathrm{p}$.

TANJI, K.K. (1990): The nature and extent of agricultural salinity problems.- ASCE Manuals and Reports on Engineering Practice, No. 71.-Am. Soc. Civil Eng., New York, 1-17.

TANJI, K.K., (1996): Agricultural salinity assessment and management.- American Society of Civil Engineers, New York 10017, 393 p.

VILLARREAL-FUENTES, J., LEVRESSE, G., NIETO-SAMANIEGO, A.F., ALEXANDRE, P. \& CORONA-ESQUIVEL, R. (2016): Geochemistry and geochronology of the Sierra de Gomez Limestone-hosted U deposit, Chihuahua: implications for distribution of Rio Grande rift mineral deposits in northern Mexico.- Ore Geol. Rev., 76, 19-34

WANG, F., GAO, J. \& ZHA, Y. (2018): Hyperspectral sensing of heavy metals in soil and vegetation: Feasibility and challenges. - ISPRS Journal of Photogrammetry and Remote Sensing, Vol. 136, 73-84.

WANG, X., ZHANG, F., DING, J., KUNG, H.T., LATIF, A. \& JOHNSON, V.C. (2018): Estimation of soil salt content (SSC) in the Ebinur Lake Wetland National Nature Reserve (ELWNNR), Northwest China, based on a Bootstrap-BP neural network model and optimal spectral indices.- Sci Total Environ, 15; 615: 918-930.

ZHANG, F., TIYIP, T., DING, J., KUNG, H., JOHNSON, V.C., SAWUT, M., TASHPOLAT, N. \& GUI, D. (2014): Studies on the reflectance spectral features of saline soil along the middle reaches of Tarim River: a case study in Xinjiang Autonomous Region, China.- Environmental Earth Sciences, 69/8, p. 2743. 